\title{
Is correction of the deformity sufficient for complete recovery from idiopathic scoliosis?
}

\author{
Angelo Gabriele Aulisa*1, Stefano Negrini' ${ }^{2}$, Marco Galli³, Andrea De \\ Matthaeis ${ }^{3}$ and Lorenzo Aulisa ${ }^{3}$
}

\author{
Address: ${ }^{1}$ Orthopaedic Department, Children's Hospital Bambino Gesù, Institute of Scientific Research, Via della balduina 6300136 Rome, Italy, \\ ${ }_{2}^{2}$ ISICO (Italian Scientific Spine Institute), Milan, Italy and ${ }^{3}$ Department of Orthopaedics, "A. Gemelli" Hospital, Universita Cattolica del Sacro \\ Cuore, Rome, Italy \\ Email: Angelo Gabriele Aulisa* - aulisa@libero.it \\ * Corresponding author
}

\author{
from 4th International Conference on Conservative Management of Spinal Deformities \\ Boston, MA, USA. 13-16 May 2007 \\ Published: 12 October 2007 \\ Scoliosis 2007, 2(SuppI I):S40 doi:I0.II86/I748-7I6I-2-SI-S40
}

This abstract is available from: http://www.scoliosisjournal.com/content/2/SI/S40

(C) 2007 Aulisa et al; licensee BioMed Central Ltd.

\section{Objective}

Aim of the study is to show that all patients that reached the complete correction of the parameter of scoliotic deformity (Cobb and Pedriolle degree) by means of orthotic treatment maintained the correction even after the early end of treatment (before the end of growth).

\section{Study design}

The study was carried out on 300 patients who underwent orthotic treatment by means of Progressive Action Short Brace (P.A.S.B.). Sixteen patients (14 females and 2 males) were selected on the basis of the following criteria:

- Complete correction of Cobb and Pedriolle degrees

- End of treatment before the skeletal maturity

Nine cases presented a thoracolumbar scoliosis and seven cases presented a lumbar curve.

At the beginning of treatment mean age was $12 \pm 1.67$ years and mean Cobb angle was $28 \pm 5.7$ degrees. Treatment lasted $25.88 \pm 1.99$ months.

\section{Results}

In all cases the complete correction of Cobb that Pedriolle parameters was maintained after the weaning from the brace. Results maintained stable at follow-up (96 \pm 2.73 months).

\section{Conclusion}

Evolution of the scoliosis is the result of the interaction between biological and mechanical factors. The biomechanical studies of the elastic characteristics of the healthy spine and the deformed one confirm the assumption, but do not solve the question of their respective role in the pathogenesis of the deformity. Clinical analysis has confirmed that the mechanical component assumes a prominent role compared to the biological factors in the pathogenesis of the evolution of the curve $[1,2]$.

\section{References}

I. Stokes IAF, Spence H, Aronsson DD, Kilmer N: Mechanical modulation of vertebral body growth. Implications for scoliosis progression. Spine 1996, 21:1162-1167.

2. Stokes IAF, Windisch L: Vertebral height growth predominates over intervertebral disc height growth in adolescents with scoliosis. Spine 2006, 31:1600-1604. 